\title{
Use of public information for road-capacity reductions: a study of mediating strategies during tunnel rehabilitations in Oslo
}

\author{
Anders Tønnesen $^{1}$ (D) $\cdot$ Oddrun Helen Hagen $^{1} \cdot$ Aud Tennøy $^{1}$
}

Published online: 22 July 2020

(c) The Author(s) 2020

\begin{abstract}
In this paper, two public information campaigns were analysed. These were related to capacity reductions, caused by maintenance work, in two main road tunnels-at Smestad and Bryn in Oslo. The paper analyses the campaigns' characteristics and their goal fulfilment. The usage of social media to inform and communicate with travelers and inhabitants is highlighted. We find a high level of outreach of the campaigns and satisfaction among travelers with the information received. However, there are substantial differences between the information campaigns. The Smestad campaign had clear elements of mass-media scaremongering. Here, it is reasonable to attribute the traffic reduction in the first days after the capacity reduction to the massive media headings in advance about possible congestion and chaos. In contrast, the Bryn campaign was more multi-faced and lasted longer. Through massive neighbourhood information and use of social media, this campaign extensively encouraged and advised travelers on how congestion could be avoided if people travelled less by cars during the rehabilitation phase. Further, the Bryn campaign directed social media posts and digital advertising towards specific groups at specific times, and by doing so exemplifying audience targeting and the use of information campaigns to legitimate public interventions. While traditional media provided a strong basis for mass information in the early stages of both tunnel rehabilitations, social media had a clear mediating role at Bryn. Last, while describing management of deviant traffic situations, the paper also feeds into discussions of how to facilitate urban-transport change towards reduced car usage.
\end{abstract}

\section{Abbreviations \\ NPRA National Public Roads Administrations \\ FB Facebook}

Anders Tønnesen

ato@toi.no

1 Institute of Transport Economics, Gaustadalleén 21, 0349 Oslo, Norway 


\section{Introduction}

The usage of road space is central in urban debates. Among other things, issues concern how free-flowing traffic should be ensured, what sufficient road capacity entails and how shifts towards more sustainable transport should be implemented. This paper's analysis of the public information campaigns connected to the rehabilitation of two central tunnels in Oslo relates to all these issues.

The information campaigns, which constitute the empirical cases, were initiated by the National Public Road Authority (NPRA) when the Smestad and Bryn tunnels had reduced capacity for 12 and 14 months, respectively. The paper takes as a point of departure that well-designed information campaigns are important both to mediate traffic challenges during periods of capacity reductions and for building legitimacy for public interventions. In relation to the latter we highlight NPRA's use of social media to inform and communicate with travellers and neighbours.

The paper is part of the larger project Knowledge for future effective and environmentally sustainable urban transport systems, shortened to BYTRANS. The project investigates adaptations to, effects and consequences of several transport-system changes in Oslo. Seeing the two tunnel-capacity reductions and their associated information campaigns as an opportunity for doing novel research, the paper seeks to answer the following research questions:

1. What characterised the motivation, content and execution of the NPRA information campaigns?

2. To what extent did the information campaigns fulfil the intentions with respect to outreach and effects?

3. How did the use of social media for information and communication work out?

Answering these questions will provide useful knowledge for public authorities aiming at reducing negative effects of long-term temporal infrastructural disruptions in urban transport systems. While the capacity reduction was related to maintenance work and not part of a political strategy to reduce traffic volumes, insights from the paper reach beyond the realms of traffic management in deviant traffic situations, relating to the discussion of how to facilitate transport-system change in urban areas with lower shares of private car usage.

\section{Theoretical framework}

The point of departure for public information campaigns is a typical societal problem to be solved. The campaign is initiated as a response aiming to change behaviour through affecting the knowledge, attitudes or skills of the receiver (Ostergaard 2011). However, a challenge occurs when public campaigns are used as a quick fix to avoid addressing deeper structures. Løding and Vibe (2010), for example, point to the many anti-bullying school campaigns having limited effect as the causes of bullying are found in the quality of the learning environment rather than a low level of awareness. 


\section{Analytical categories to study information campaigns}

To structure the study of the two Norwegian information campaigns, we apply three analytical categories-motivation, content strategy and execution strategy. While the first was constructed by the researchers, the latter two stem from Delhomme et al.'s (2009) work on transport-communication campaigns.

Motivation is applied to analyse the overall goal and purpose of conducting a given information campaign. It covers the challenge to be solved and intentions of the actors involved.

Content strategy involves decisions about what is being communicated in the information campaign. Delhomme et al. (2009) point out that a campaign can have a rational or emotional approach. In a similar way, a distinction can be made between normative approaches (e.g. changed behaviour serving a common good) and fear approaches (e.g. if behaviour is not changed, a given system is likely to collapse). The effects of fear-based campaigns are far from clear and unequivocal. Based on a literature review on fear-based campaigns, Carey et al. (2013) conclude that they often have limited effect. Delhomme et al. (2009) state that they can be effective but only in specific situations. They explain that, before carrying out fear-based campaigns, there is a need for doing thorough research and pre-testing to clarify the characteristics of the threat. On the other end of the spectrum of emotional campaigns, messages can be designed to create a positive emotional response, for example, by using humour.

Execution strategy involves considerations of how public information will be given and by whom. A central element is tailoring campaigns to reach specific groups and subpopulations. Audience targeting has been found to be beneficial for encountering diverse societal challenges, such as in health-awareness campaigns (Hair et al. 2018) and healthcrisis management (Jin et al. 2019).

In the transport sector, Taniguchi et al. (2013) illustrate the effectiveness of audience targeting, finding that higher levels of public-transport usage are associated with the provision of specific and motivating information. The target audience is typically a specific group based on one or more selection criteria (e.g. level of education, current work and location of dwelling). According to Delhomme et al. (2009), such narrowing helps elaborate a more effective content strategy and choose the best communication channels for reaching that audience. Road-safety research shows that campaigns are more effective when focussed on specific groups (see Delhomme et al. 2009; Hoekstra et al. 2011; Wundersitz et al. 2010). Further, it has been claimed that identifying the target audience allows planners to consider road users' level of knowledge, beliefs and/or behaviour and the best way of reaching them (Delhomme et al. 2009). Wundersitz et al. (2010) emphasise that knowing more about the target audience results in a greater chance of developing an effective campaign that may influence attitudes and behaviour.

\section{Mass media, social media and technological innovation}

Issues of reducing road capacity are typically highly engaging. Whether it is a temporary tunnel rehabilitation or the politically determined reallocation of road space, capacityreducing initiatives are often met by arguments that change will result in congestion and chaos, causing problems for commercial traffic and people in their everyday lives. However, this is not necessarily supported by research. In their much-cited study, Cairns et al. 
(2002) analysed 70 case studies of road space reallocation from 11 countries. They found that 'predictions of traffic problems are often unnecessarily alarmist, and that, given appropriate local circumstances, significant reductions in overall traffic levels can occur' (13). There are multiple reasons for this. One relates to the traffic-regulating mechanisms of congestion itself: While congestion results in costs and disadvantages, it also regulates cartraffic volumes (Banister 2008; Noland and Lem 2002). Another factor is the role of public campaigns and mass media in the wake of potential congestion.

Several studies have illustrated how anticipated and announced traffic jams failed to materialise (Cairns et al. 2002; Frey et al. 2011). In this way, providing travellers with information on travel options has the potential to enhance efficient use of the transport system. This is in line with Jin et al.'s (2019) two-step recommendation for crisis-campaign management, which is to make people aware of the risks and identify clear actionable steps to reduce them.

Road maintenance may affect the quality of the transport system. With reduced road capacity, levels of congestion may rise, making car driving less attractive. Researchers have described how travellers respond to changes in different ways. Adaptive strategies include changes in driving routes, timing of journeys, transport modes and travel frequency (see Cairns et al. 2002; Downs 2004; Frey et al. 2011). Research has also illustrated how underlying traffic conditions influence travel information usage. For example, use of technological traveller information has been found to increase with expected congestion or volatility in travel times (Petrella and Lappin 2004; Chorus et al. 2006).

In addition to new technology, new communication platforms, such as social media, provide important tools. Mass-media campaigns have been connected to health awareness. Bafunno et al. (2019) emphasise the importance of mass-media campaigns in relation to smoking, while Christensen et al. (2019) find a similar effect for alcohol consumption. Nevertheless, there are studies finding limited effects of mass media campaigns, including a literature review by Phillips et al. (2009). Further, research points to the need for applying traditional mass media in combination with other platforms, such as social media (Jin et al. 2019). The argument is that the use of multiple sources enables public campaigns to better reach different population groups.

\section{Information campaigns and the legitimacy of public interventions}

Another dimension of information campaigns relates to the legitimacy of public interventions. For example, congestion, delays and uncertainty resulting from roadwork may trigger dissatisfaction and resistance among travellers. In contrast, sufficient information may reduce such tensions. Cairns et al. (2002) emphasise the need for well-designed information schemes if capacity-reduction projects are to succeed. Among the highlighted elements are the following: (1) the need for monitoring controversial issues (so critics can be met with facts, which should be readily available as soon as possible) and (2) using the media and public consultation work to inform travellers about the probability of problems occurring.

The double role of campaigns to handle concrete challenges and secure the legitimacy of public interventions also supports the use of multiple sources in public campaigns. Referring to crisis management, Liu et al. (2011) emphasise how different media play various roles at distinct crisis stages. They claim that, when crises are initially revealed traditional media represent a highly important information source. However, in later crisis 
stages, social media may play a more important role as it forms part of a basis for moral support.

\section{Research design and data collection methods}

Yin ([1994] 2003) describes a case study as an empirical inquiry that 'investigates a phenomenon within its real-life context' (13). In this paper, two information campaigns-one connected to the Smestad and one to the Bryn tunnel rehabilitation-constitute the cases. ${ }^{1}$ There are clear inter-linkages between the two campaigns. They both concern the same overall tunnel rehabilitation project, many of the same actors are involved and they partly overlap in time. While this could suggest a single case design (cf. Yin [1994] 2003), they have been treated as separate cases due to the large differences between the campaigns.

While the rehabilitation work in the Oslo area comprises 10 tunnels, a focus on the campaigns related to the Smestad and Bryn tunnels was chosen for several reasons. In both tunnels, the road capacity was reduced from four to two lanes, and the rehabilitation was long lasting (12 and 14 months respectively). The Smestad tunnel was the first of the Oslo tunnels to be rehabilitated; this involved high uncertainty among travellers, media and policy actors in terms of traffic effects. Further, both tunnels are central to the Oslo transport system. The eight other Oslo tunnels were less relevant for multiple reasons: (1) the rehabilitations had not yet started at the time of fieldwork, (2) the rehabilitation work was less extensive in some of them (involving closure only at night or during weekends/holidays) and (3) the levels of traffic passing through the tunnels were lower.

As part of the larger BYTRANS project, this study had access to a range of qualitative and quantitative data sources (see Table 1 in Appendix A). Some were studied explicitly to highlight the use of public information. Other data sources, which have been analysed and used in other parts of the BYTRANS project, serve as background information and input for the analyses in this paper. The project has analysed how the capacity reductions affected traffic volumes ${ }^{2}$ and average rush-hour speed, as well as how commuters, truckdrivers and taxi drivers adapted to and experienced the situation (see Tennøy et al. 2016, 2019); other articles focussing on these issues are under production).

Surveys were conducted in the BYTRANS project. Two geographical areas in the vicinity of the Smestad and Bryn tunnels were defined, and respondents employed in businesses in these case areas were asked questions related to the tunnel rehabilitation work in the relevant (nearby) tunnel. Some questions concerned the information campaign, and the related answers are important data in this paper. The number of respondents employed in businesses within the Smestad case area (conducted in 2015) were 313, while the number of respondents in the Bryn case area (conducted in 2016) were 1029. Open-ended questions concerning the information campaign were loaded into NVivo, a software program

\footnotetext{
1 The two information campaigns are seen as unique cases; cf. Yin's ([1994] 2003) categorisation. While the road authorities conduct information campaigns regularly, the two campaigns in focus here are categorised as unique due to the magnitude of the physical rehabilitation carried out and strategies the road authorities applied to mitigate this.

2 Data from electronic traffic counters, operated by national and municipal transport authorities, were used for analysing changes in traffic volumes and speeds.
} 


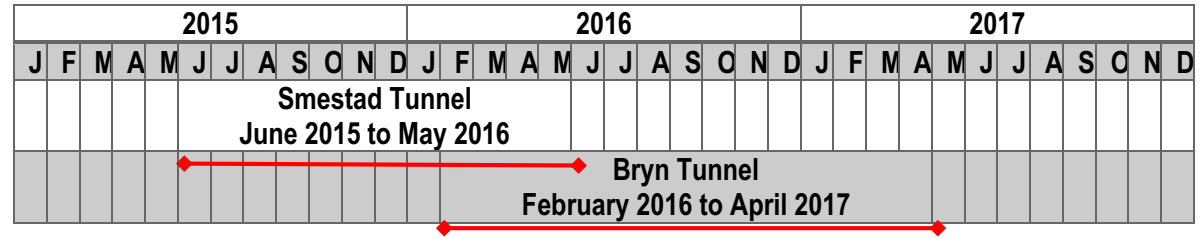

Fig. 1 Timeline for the rehabilitation of Bryn and Smestad tunnels

for qualitative analysis, and coded according to a set of defined categories. ${ }^{3}$ Parts of a much smaller survey among truckdrivers $(n=32)^{4}$ and data from three focus-group interviews with taxi drivers are also included in the material and analysed to highlight the use of public information. Moreover, two interviews with truckdrivers form part of the data material.

Data collection focussing directly on the NPRA information campaign concerned several types of data. It involved a focus group interview with NPRA representatives and qualitative interviews with four key informants. The interviews were not tied to a specific fieldwork period, and for two key informants, follow-up interviews were conducted. It also involved document studies of reports, planning and decision documents to achieve knowledge on relevant aspects of the tunnel rehabilitation and communication strategy. The analysis was conducted on the dedicated Facebook (FB) page for the Bryn tunnel for the period of January-December 2016. This webpage was established just before the rehabilitation at Bryn started, and was run by the NPRA. Finally, media coverage analysis was carried out based on frequency reports from a news database (Retriever) for January 2015-June 2017. The FB and media coverage analyses focussed on the time immediately before and during the tunnels' capacity reduction.

\section{The tunnel rehabilitation and the effects on traffic}

As a response to an EU tunnel-safety directive (European Parliament 2004), 10 tunnels on Oslo's main-road system were slated to undergo substantial rehabilitation between 2015 and 2020, including the Smestad and Bryn tunnels. For these tunnels, the rehabilitation works required closing two of four lanes at a time, while two-way traffic was permitted in the open tube. The capacity reduction in the Smestad tunnel lasted for 12 months, from June 2015 to May 2016 (see Fig. 1). In the Bryn tunnel, it lasted for 14 months, from February 2016 to April 2017.

These are dual tunnels, carrying approximately 50,000 (Smestad) and 70,000 (Bryn) vehicles a day (annual average daily traffic, AADT). They are located on the main ring road (Ring 3) in Oslo (see Fig. 2). Ring 3 distributes traffic between different parts of the city, region and country. Traffic levels are similar in both directions, including in rush hours.

\footnotetext{
3 The NPRA main office is located in the Bryn case area, and representatives of this body took part in the survey. These employees had a high response rate, and this especially affected the answer on where they had received information; more than other respondents, they pointed to their employer, the NPRA.

4 While the truckdriver survey had relatively few respondents, self-selection tendencies are considered to have been reduced by the researchers conducting on-site interviews at the drivers' waiting stations. A large proportion of the drivers who were approached agreed to be interviewed.
} 


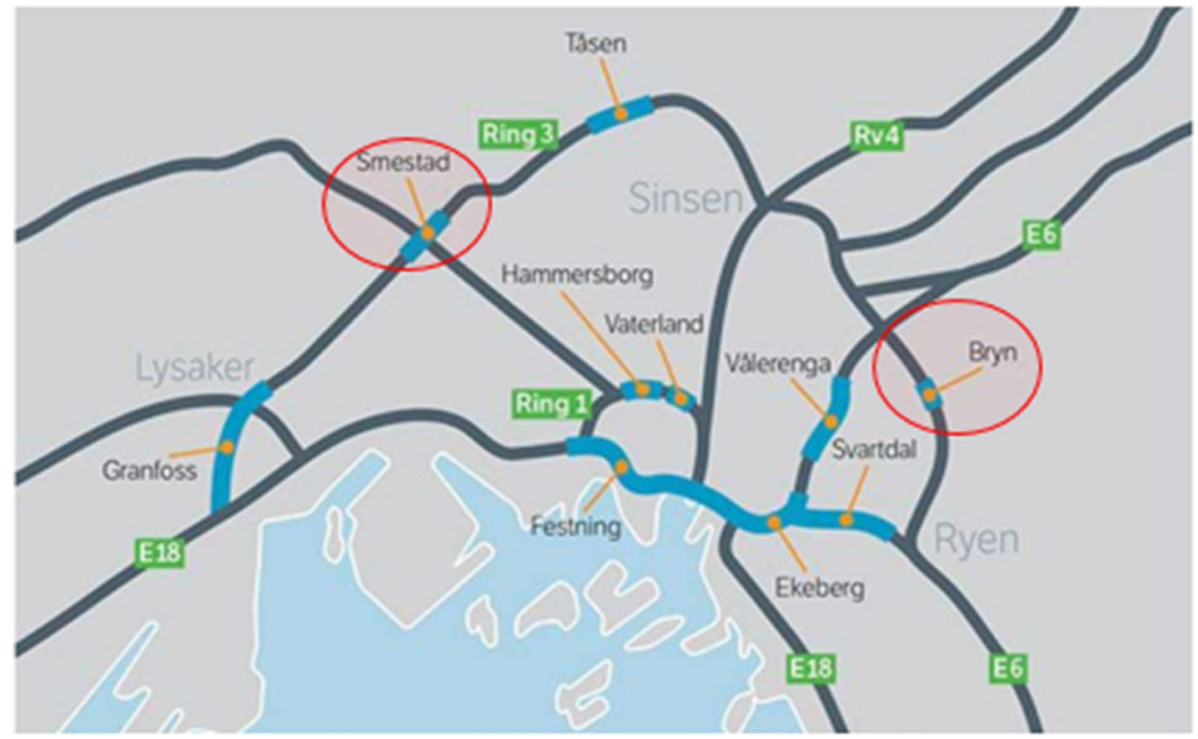

Fig. 2 Location of the Smestad and Bryn tunnels in Oslo's urban road system and the eight other tunnels in the Oslo tunnel rehabilitation project. Source: NPRA

The speed limit is normally $70 \mathrm{~km} / \mathrm{h}$, but this was reduced to $50 \mathrm{~km} / \mathrm{h}$ during the rehabilitation periods. When the rehabilitation works were finished, the tunnels regained the same capacity as before the rehabilitation works started.

The traffic situation for Smestad tunnel is measured by the traffic counter in the Tåsen tunnel, $3.8 \mathrm{~km}$ east of the Smestad tunnel. In a normal situation, before the capacity reduction, average traffic volumes in the rush hours on workdays, for both directions, comprised approximately 10000 (morning) and 9000 (afternoon) vehicles. Average speed levels in morning and afternoon rush hours on a 9-km road link that includes the Smestad tunnel were approximately $70 \mathrm{~km} / \mathrm{h}$ in morning rush hours and $60 \mathrm{~km} / \mathrm{h}$ in the afternoon. The traffic on this part of Ring 3 was significantly reduced the first day after the capacity reduction (down 3\%, 3500 vehicles, in the morning rush from 07.00 to 9.00 for both directions, and down $33 \%, 3200$ vehicles in the afternoon rush from 15.00 to 17.00), and average speeds in rush hours were higher than in the normal situation (Tennøy et al. 2016). On the second day after the capacity reduction, traffic already started to increase. When measuring the traffic situation three months later, traffic volumes were back to normal levels. Although the road capacity was reduced from four to two lanes, only small increases in delays were found. Our understanding of this is that the Smestad tunnel had enough capacity, after the rehabilitation started, to carry the same traffic load as before (about 1400 vehicles per hour, one direction). The traffic is about equal in both directions, including in rush hours, and much of the traffic is dispersed throughout the day. Hence, peak traffic volumes are probably lower than they are in many other urban roads with similar AADTs.

In the Bryn tunnel, the average traffic volumes for both directions in the rush hours on workdays were approximately 12,000 (morning 7.00-9.00) and 11,000 (afternoon 15.00-17.00) vehicles shortly before the capacity was reduced. Average speed levels on the road link that includes the Bryn tunnel corresponded with the $70 \mathrm{~km} / \mathrm{h}$ speed limit in the morning rush hours, while traffic flow was reduced to around $50 \mathrm{~km} / \mathrm{h}$ in the afternoon. 
During the capacity reduction, road users adapted in ways resulting in a significant decrease in traffic volumes through the tunnel, by 26-34\% in rush hour and $20-23 \%$ per day (Tennøy et al. 2019). Speed limits were reduced to $50 \mathrm{~km} / \mathrm{h}$, and the average measured traffic speeds were significantly reduced to $30-40 \mathrm{~km} / \mathrm{h}$. The southbound traffic in afternoon rush hour was different; here, average measured speeds were reduced from about $30 \mathrm{~km} / \mathrm{h}$ to about $20 \mathrm{~km} / \mathrm{h}$.

\section{The NPRA information campaigns}

\section{Motivation and overall communication goals}

The overall communication goal of the NPRA frames the information campaign of the tunnel rehabilitation projects. Here, it is stated that the NPRA 'is to be perceived as an open and user-friendly competence network working with care for people and the environment to ensure travellers a safe and efficient journey' (NPRA 2015a: 3). In accordance with this goal, an information strategy was prepared when the 10 Oslo tunnels were to be rehabilitated (NPRA 2015a), stating that those directly affected by the rehabilitation work were to receive information prior to the capacity reduction and be encouraged to use means of transport other than cars. The underlying reasons for the tunnel rehabilitation (e.g. sharpened EU tunnel-safety requirements) were not part of the main message in the communication strategy.

The NPRA seems strongly mobilised by a wish to avoid extensive traffic chaos and dissatisfaction among road users. The information campaigns were thus linked to a desire for building legitimacy for the public intervention of tunnel rehabilitation. However, the NPRA also seized the opportunity to test new communication tools for travel-system management. As noted by an NPRA informant, 'We had the opportunity to show our abilities. We could not afford to fail [in terms of traffic collapsing], and we got more people working with public information'.

\section{Content}

A key element communicated throughout the information campaign was a timetable showing the estimated duration for each tunnel rehabilitation and what type of closure could be expected (e.g. whether rehabilitation involved nights/weekends or more long-term closure). A main message in the information campaign was that, during periods of overlapping tunnel rehabilitation - like for Smestad and Bryn - there would be significant capacity reduction in the road transport system. It was also emphasised that the tunnel works would lead to more congestion and delays. The main message for the Smestad tunnel was rather alarmist, with headings like, 'If no one changes travel habits [i.e. how and when people travel], it may take up to four hours to drive from Sinsen to Smestad [a distance of $7 \mathrm{~km}$ ]' ${ }^{5}$ When the Bryn tunnel was to be rehabilitated, the message was somewhat different: 'Avoid congestion while the Bryn tunnel is partially closed! Leave the car; use public transport, cycle or walk!'. ${ }^{6}$ While this paper focusses on the information campaigns, it should be noted that

\footnotetext{
5 National newspaper $V G, 1.6 .2015$.

6 Message posted on the NPRA FB page, 22.02.2018.
} 


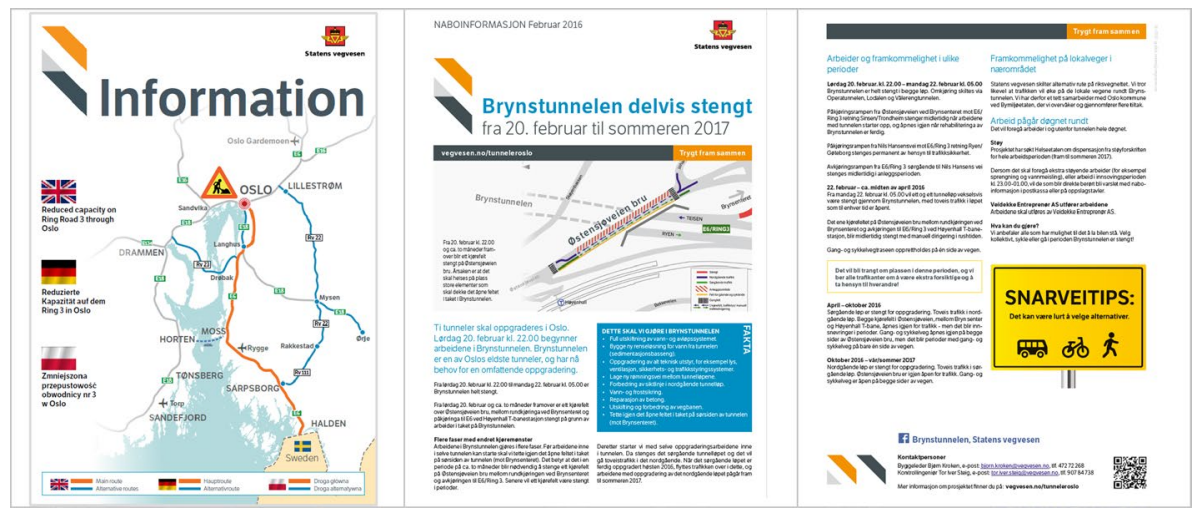

Fig. 3 Flyers describing the work and consequences of tunnel rehabilitation (two-page Norwegian flyer in middle and to the right). Source: NPRA

the NPRA strategy also involved mitigating measures, such as signposted speed reductions, temporary park-and-ride facilities and temporary public-transport improvements.

\section{Execution: Smestad information campaign}

The NPRA has extensive experience in implementing various communication measures before major work on the road network. These traditional measures, described below, were used in the Smestad information campaign:

Key NPRA personnel available: A central point in the strategy was that key NPRA personnel, including the project manager, were to be highly accessible to all those with questions about the capacity reduction. Availability of key personnel was emphasised to reduce uncertainty and frustration among travellers and ensure good co-operation with other agencies.

Stakeholder analysis: Interest analysis was one of the first activities in the communication work for each tunnel. It included mapping and prioritisation of target groups, as well as detection of specific challenges arising with the rehabilitation and finding solutions for them.

Local community information: Flyers describing the work and mitigating strategies were made and distributed locally. Flyers were made in several languages as illustrated in Fig. 3.

NPRA webpages: On the NPRA website, general information on the tunnel rehabilitation and information about each tunnel repair and upgrade were presented. The agency considers this a main information channel (NPRA 2015a). The website was used both to communicate about the ongoing work and its effects on traffic; the information was given in Norwegian and sometimes English. Flyers with local information were also made available here.

Dialogues with schools and parent-teacher associations: Schools considered to be affected by the rehabilitation work were mapped in advance. This was done by the NPRA in co-operation with the municipality. Thereafter, dialogue was established between the school leadership, parent groups, municipality and NPRA representatives. 
Electronic roadside boards: On the central main routes, large textboards warned about the risk of congestion and encouraged people to travel by public transport. In addition, real-time information was given for a limited number of alternative driving routes, providing drivers a basis for route selection.

Facilitating news coverage: The NPRA sent information and press releases to local and national newspapers. In addition, press seminars were held. As the first rehabilitation project, the Smestad tunnel received massive media coverage both prior to the capacity reduction and when the work commenced.

Advertisement, radio and news media: Advertisements in both news media and radio were used to inform the public about the new traffic situation at Smestad and Bryn. However, as described in the next section, a shift occurred, with more advertising on digital news media and a higher level of audience targeting in the Smestad campaign compared with that of Bryn.

\section{Execution: Bryn campaign}

Turning to the Bryn campaign, the NPRA shifted its execution strategy. It employed all the information measures that had been used in the Smestad campaign and introduced novel measures, some new to the NPRA. While paper-based and digital media coverage was highly important when initiating the work of the Smestad tunnel, one could not expect the same news coverage for Bryn. Long-term tunnel rehabilitation was no longer a new and unknown phenomenon in Oslo, and the experience from Smestad was that the traffic flow did not collapse with the capacity reduction.

The rehabilitation at Bryn proceeding Smestad enabled the NPRA to draw on experiences from the latter. Before the Bryn rehabilitation began, the NPRA decided to apply new types of communication measures as a supplement to the traditional ones. As explained by a key informant from the NPRA,

As an agency, we can plan a lot. However, the extent to which media choose to cover an issue cannot be planned. Before the Smestad rehabilitation, we worked extensively with the media, and there was tremendous coverage. We got the effect we wanted: Travellers were informed and enabled to potentially choose other modes of transport than private cars. Thus, when the Bryn rehabilitation was about to start, we continued with what had worked well and asked the question of what more we could do. We had to reach the travellers in a new way because you don't get the same media coverage twice in one [overall] project. As a result, we decided to use advertising more.

The NPRA decided to engage a public relations (PR) agency to reach affected traveller groups more effectively. In autumn 2015, an acquisition was announced for the preparation and distribution of an information campaign. The Bryn tunnel was the first major project the campaign targeted. In the announcement, the NPRA emphasised that the supplier should offer 'creative expression and production of material for several platforms, with an emphasis on digital channels' (NPRA 2015b: 4). With the involvement of the PR agency, the use of social media and advertising on digital platforms became a more central part of the information campaign.

Digital advertising: Advertising on digital platforms facilitated more extensive audience targeting, allowing the NPRA to reach residents in specific geographic areas at defined times (e.g. commuters likely to travel via the Bryn tunnel). This type of advertising 
Fig. 4 Examples of digital advertising. Left: 'The Bryn tunnel will partially be closed from February 22'. Right: 'Shortcut tip: It could be smart to choose alternatives'. Source NPRA
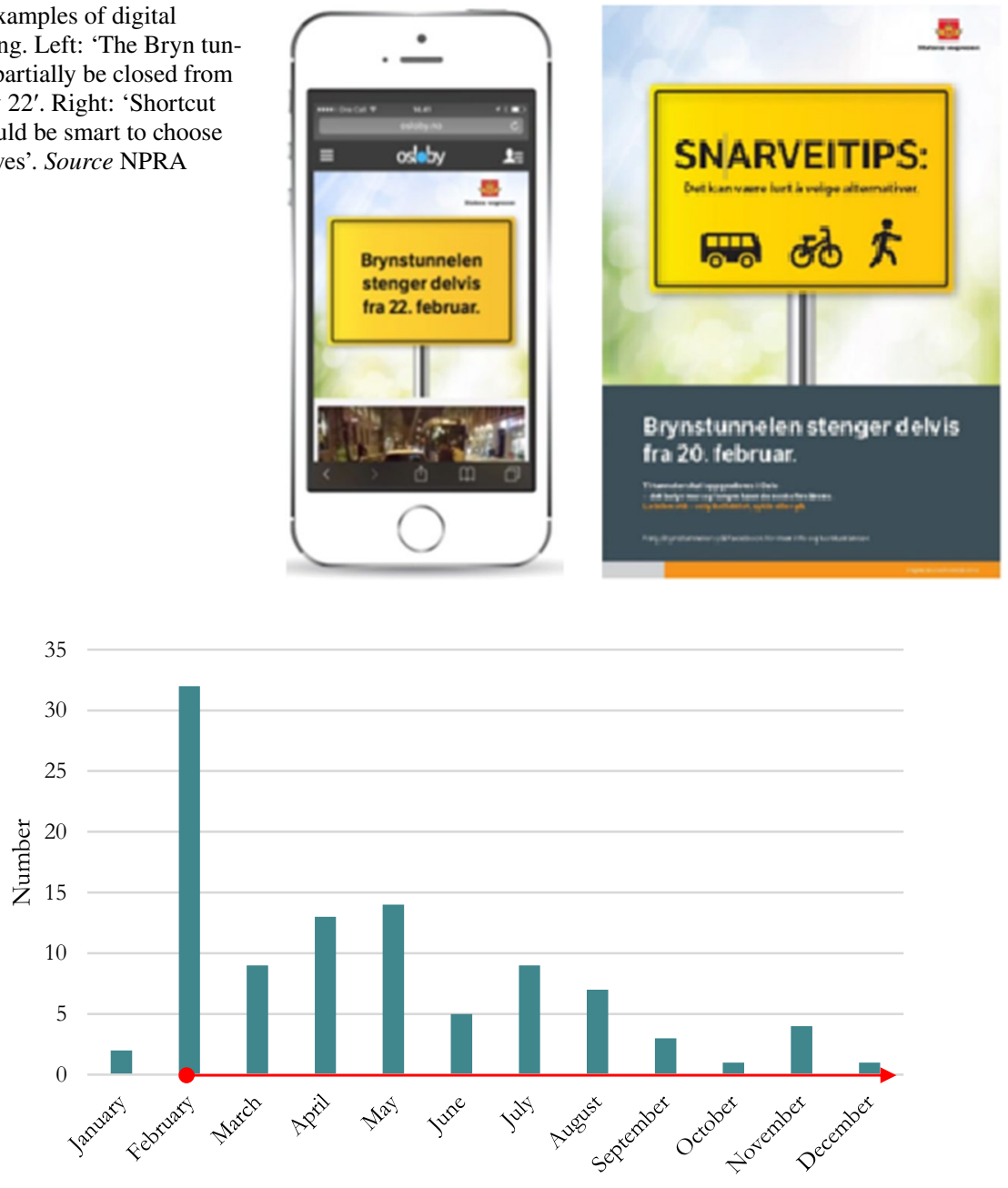

Reduced capacity Bryn

Fig. 5 Frequency distribution of the main entries by the National Public Roads Administration on the 'Bryn tunnel' FB page, 2016

was distributed in both digital newspapers and social media, focussing on the idea that driving through the tunnels would lead to delays, while choosing active modes of transport or public transport would represent a 'shortcut' (Fig. 4). Such advertising represents a new form of targeting information work for the NPRA.

Social media: While Twitter was applied for the rehabilitations at both the Smestad and Bryn tunnels, the use of FB marks a clear difference between the two. An FB page called Bryn tunnel ${ }^{7}$ was created three weeks before the rehabilitation started. In

7 The page is still in use, but the name has been changed to Tunnels of Oslo, NPRA. 
Fig. 6 Advertisement of NPRA ski service at commuter parking. Source: NPRA

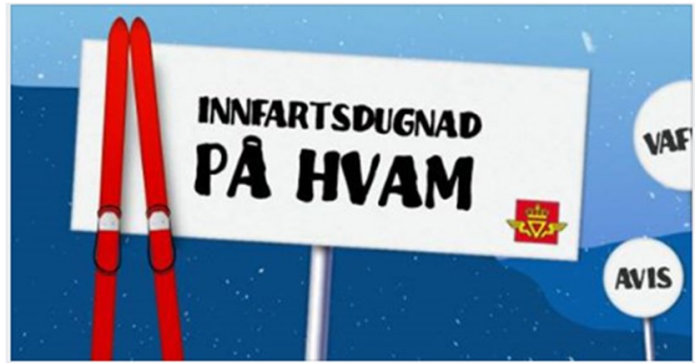

Nov. Statens vegvesen prepper skiene dine

30. Offentlig · Arrangør. Statens vegvesen Region øst

January-December 2016, covering the time before and during the repair and upgrade of the tunnel, the NPRA published 104 posts on the FB page, addressing comments and questions. Figure 5 shows that the NPRA added the most posts in February 2016, immediately before and after the capacity reduction. Looking more deeply into the content, the most applied type of post describes how traffic is affected by the rehabilitation work (as the main element in the post).

In co-operation with the PR agency, creative efforts were made to contact and communicate with a broad audience. Music playlists were created (and published on FB), humorously including songs like 'Tunnel of love' (Bruce Springsteen) and 'Road to hell' (Chris Rea). Humour was also used in a radio commercial staged as a conversation between the Smestad and Bryn tunnels. A last example of creative communication is that the NPRA offered a cross-country ski service as a stunt to promote commuter parking at the urban outskirts (reducing traffic into the city), as shown in Fig. 6.

Campaigns were also conducted with the distribution of information, coffee and buns at several metro stations, and multiple contests were launched. Two videos were made and published on FB, one about winter cycling and one describing the rehabilitation of the Bryn tunnel. They were viewed 1,32,000 and 1,31,000 times, respectively. The films and other NPRA posts were promoted through the FB advertising system. In this way, they were strategically directed towards specific population groups at certain times. The strategy was to make the posts visible in the FB feeds of people thought to be especially affected by the rehabilitation work, among them, commuters travelling through the area on their way to work.

\section{Resources used for the information campaign at NPRA}

It is difficult to estimate total campaign-resource usage for the two tunnels and separate between them. While the NPRA does not have an exact account, an overall description can be made. In terms of manpower, there was mainly one person dedicated to the information work for Smestad. In the week of the capacity reduction, when the media pressure was at its peak (see "Main information sources"), assistance was provided by two other communication advisors at the NPRA. Other than this, only small amounts of resources were used for media advertising (web and paper). For the Bryn tunnel, two communication advisors were engaged six months before the rehabilitation started. From about two months before 


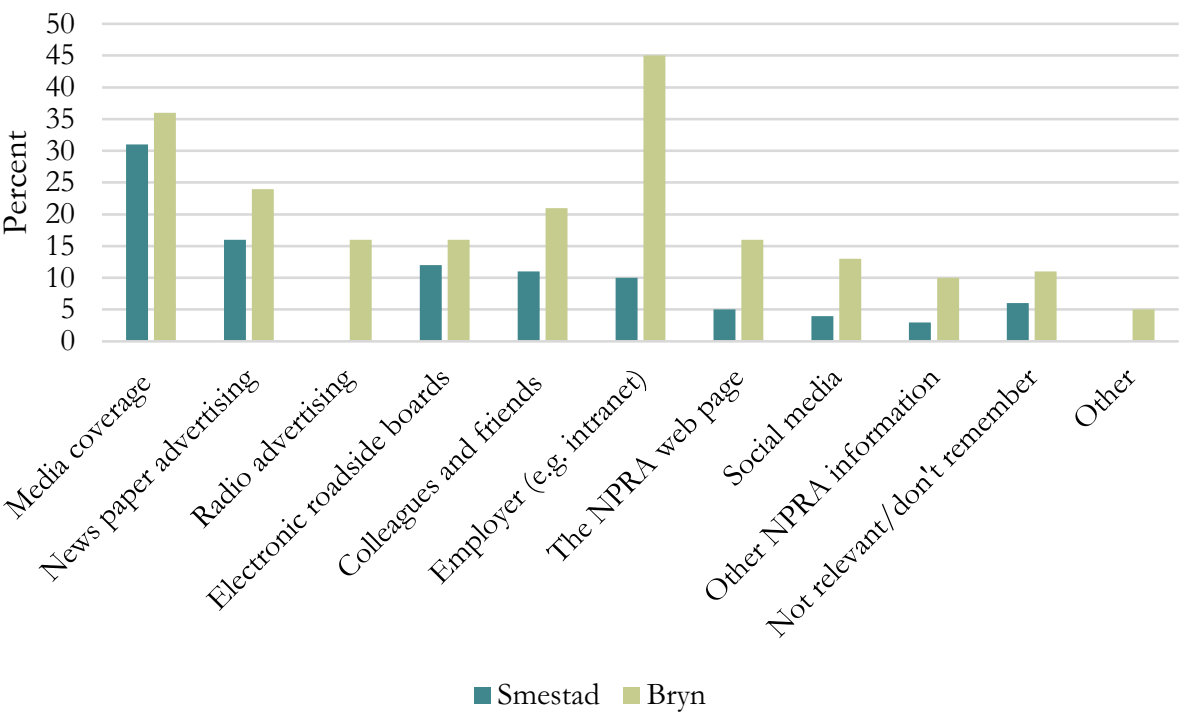

Fig. 7 Commuters' answers to the question, 'Where did you get information from? Tick up to three of the most important sources of information'. Smestad: $N=313$, Bryn: $N=1029$ (Fig. involves small differences between the surveys in terms of answer categories and wording in questions asked the respondents)

until two months after the capacity reduction was initiated, they were assisted by an additional advisor. While one of the NPRA employees was full-time engaged with the Bryn tunnel during the whole campaign period, the others also had other tasks. An advisor made the following comparison about the work at the two tunnels:

Beyond the extensive use of social media at Bryn, the kind of information work conducted for the two tunnels was much the same. But it was done at a higher level for Bryn. Among other things, we distributed flyers to the whole district-about 40,000 inhabitants - whereas at Smestad, they were only distributed to a couple hundred.

In terms of resources used externally, the agreement with the abovementioned PR agency was a two-year contract (with the possibility for a two-year extension), worth about $€ 39,000$. While this sum also involved information for other tunnels, it has been suggested that about $90 \%$ was used for the Bryn tunnel.

\section{Outreach and effects of the campaigns}

\section{Main information sources}

The two commuter surveys show that media coverage and advertising in traditional media were central information sources for commuters affected by the two tunnel projects (see Fig. 8). The same pattern is evident in the smaller truckdriver survey; editorial media coverage is the most reported source of information. The employer is also an important source of information, although the high level for Bryn shown in Fig. 7 is influenced by the high number of NPRA respondents in this survey. The truckdriver data material (survey and 


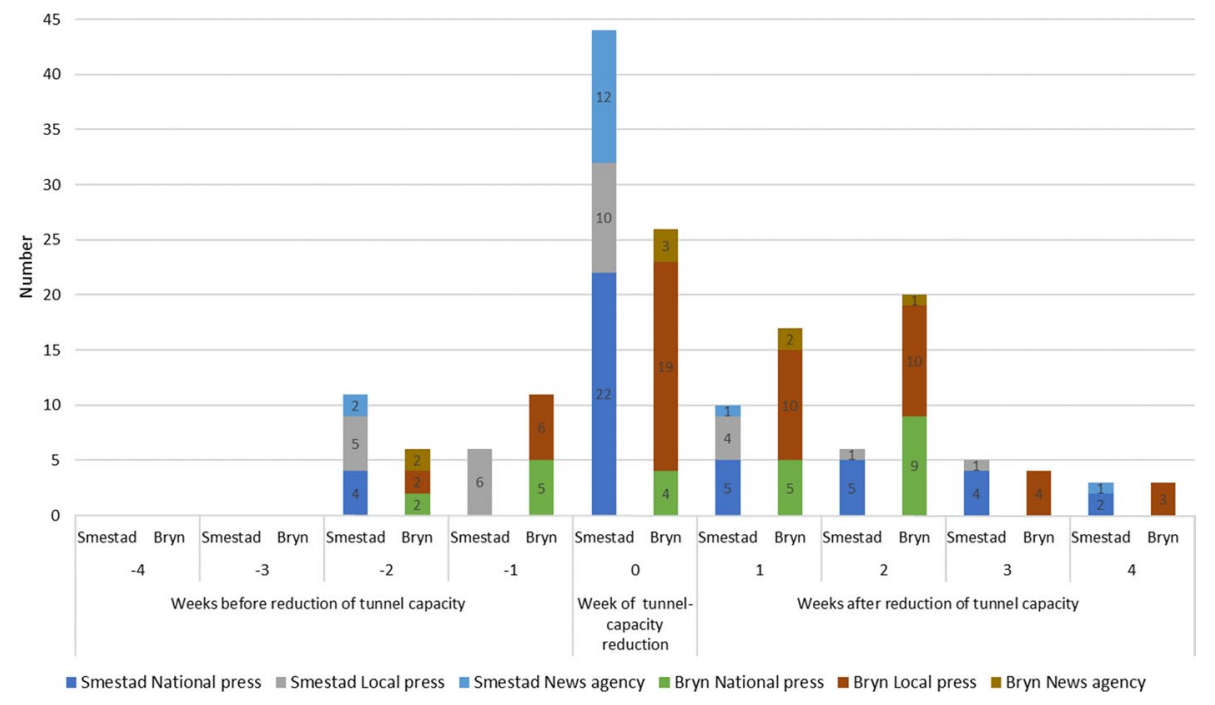

Fig. 8 Media coverage (Editorial media coverage and articles based on the free-text searches 'Smestad tunnel' and 'Bryn tunnel'. Source: News Database Retriever.) four weeks before and after the tunnel capacity was reduced. Number of articles

qualitative interviews) and taxi-driver interviews confirm that employers are an important source of information. For these groups, the organisational units that co-ordinated the drivers also distributed information about the rehabilitation among them. Addressing the issue of information, a taxi driver stated in the focus group interview, 'It was on the [driving] computer for days. The information was sent out from the central'.

Figure 8 shows the number of press articles in the weeks before and after the capacity reduction. For both tunnels, the coverage was highest during the week of capacity reduction. Smestad received by far more media attention, especially due to its higher degree of newsworthiness as the first rehabilitation project. However, while the coverage for Smestad dropped quickly over the following weeks, it remained at a higher level for the Bryn tunnel, mainly due to coverage in the local press. This may imply that the congestion challenge was more prevalent at Bryn compared with Smestad, as evident in the changes in velocity (Tennøy et al. 2016, 2019).

Looking beyond the mere amount of media coverage, there is also a difference in terms of how the two rehabilitation projects were covered by the press. According to a key informant in the NPRA, information on the Smestad tunnel was more characterised by scaremongering, highlighting the consequences if people did not change their travel behaviour. The degree of uncertainty expressed by the agency and media about what would happen with the traffic system seems to have been greater for the Smestad tunnel, since it was the first to be rehabilitated. The lesson the NPRA drew from the Smestad rehabilitation was that scenarios of traffic collapse and chaos did not materialise (Tennøy et al. 2016). Still, the NPRA was uncertain about how the tunnel rehabilitation at Bryn would affect the system, given the much higher traffic volumes passing through compared with Smestad. 


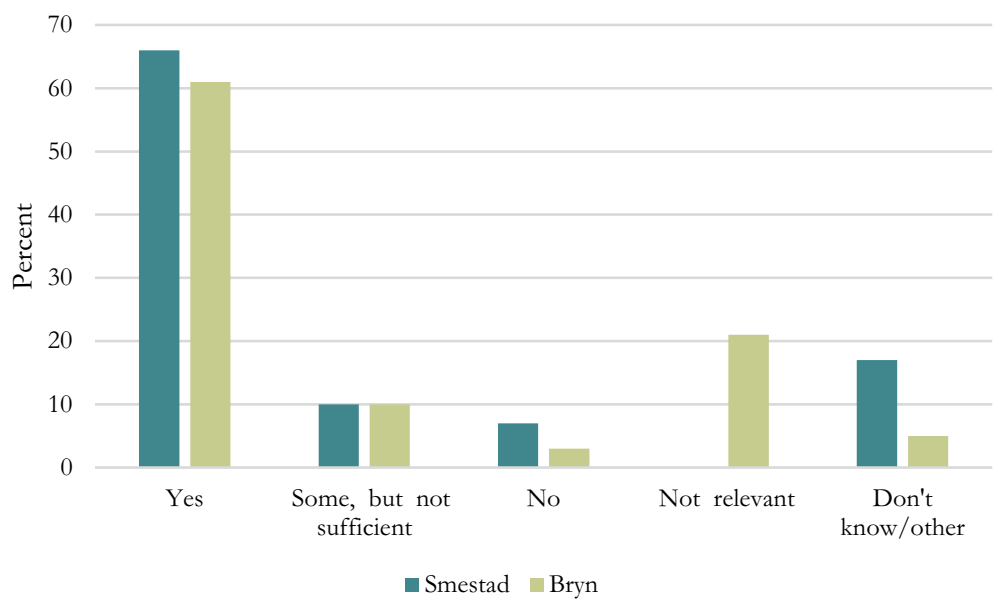

Fig. 9 Commuters' responses to the question, 'Do you feel you received sufficient information about what was going to happen before work at Smestad and Bryn tunnels started? Smestad: $N=313$, Bryn: $N=1029$

\section{User reception of the information campaign}

Travellers' satisfaction with public information prior to the tunnel rehabilitation was investigated both in the commuter and truckdriver surveys. Starting with the commuter surveys, which were conducted during the rehabilitation of both the Smestad and Bryn tunnels, there was relatively high satisfaction with the level of information. $66 \%$ of the commuters in the Smestad survey and $61 \%$ in the Bryn survey responded that they had received sufficient information before the capacity reduction (see Fig. 9). Only 7 and $3 \%$, respectively, answered that they had not received information. The high level of satisfaction with the information campaign was confirmed in the truckdriver survey, where 24 of 32 respondents said they had received sufficient information about the tunnel rehabilitation.

In the two surveys, commuters were also asked the open, optional question of whether there was anything the agency should have done differently. Text analysis revealed that only 6 of 145 open-ended answers specifically mentioned the need for more or better information in the Smestad survey. The equivalent number in the Bryn survey was 14 of 318 open-ended answers. In this question, and in both surveys, the need for better public transport services and a shorter tunnel rehabilitation period were emphasised most.

Considering the individual and focus-group interviews, the generally positive response to the information campaign can be confirmed. However, the qualitative material also nuances how the informants were more satisfied with some parts of the campaign than others. Clearly, information about the rehabilitation and its consequences for traffic reached a broad audience. Travellers knew that the capacity was to be reduced and there would be delays; however, several commuters called for more information about alternative routes and why the rehabilitation was conducted. For the NPRA, it was a deliberate choice not to provide information about detour options on local roads, partly based on traffic-safety considerations. As an NPRA representative stated, 'Extensive 


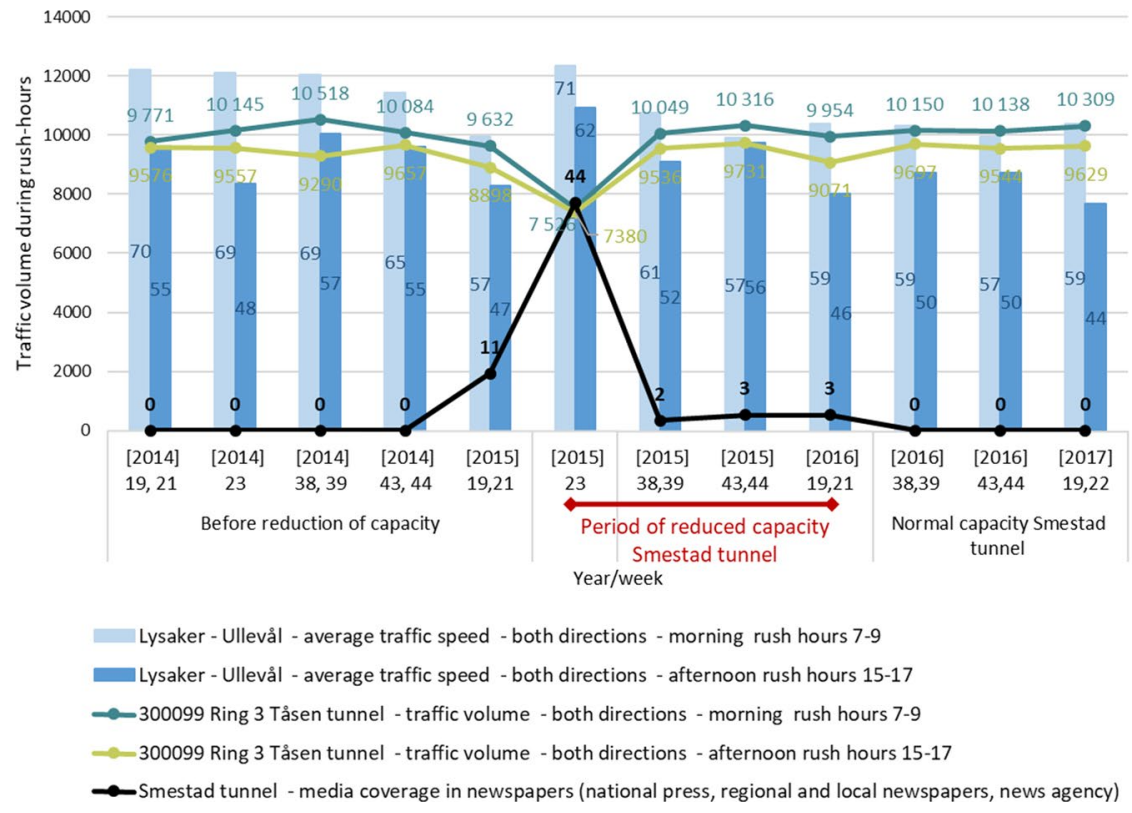

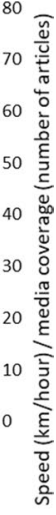

Fig. 10 Smestad tunnel: media coverage, average traffic speeds in rush hours on the road link including the Smestad tunnel and average traffic volumes (in rush hour at the nearby traffic counting point Ring 3 Tåsen tunnel; total traffic, both directions) in selected weeks before, during and after the Smestad tunnel capacity reduction

traffic on narrow roads is not good. It only takes one truck making a wrong turn and then starting to back up, and you'll have complete chaos'.

The truckdrivers confirmed that the information campaign reached them, both in the survey and qualitative interviews. They contrasted the level of information about the rehabilitation project with the general lack of information on other types of road closure, a point supported by a taxi driver in the following comment: 'Concerning the tunnel rehabilitation, there has been good information, as I understand it. But otherwise, when it comes to closures of streets elsewhere in Oslo, it's a disaster'.

\section{Effects on travel behaviour}

The effects of information can also be studied by combining media analysis and traffic registrations (Tennøy et al. 2016, 2019). Figure 10 combines three different data types for Smestad, namely, media coverage, traffic speed and traffic volumes. During the week of capacity reduction at Smestad, there was not only a peak in media coverage but also a clear reduction in traffic volume, as well as higher average speed than usual. The announced traffic chaos had not materialised. It is reasonable to attribute the traffic reduction in the first days after capacity reduction to the media headings about possible queues and chaos. When the travellers discovered (as reported by media) that the traffic was flowing smoothly despite the capacity reduction, the traffic volume quickly returned to the same level as before. The week after the capacity reduction was introduced, the traffic volumes were already roughly as they had been. The average speed did not decrease significantly in the 


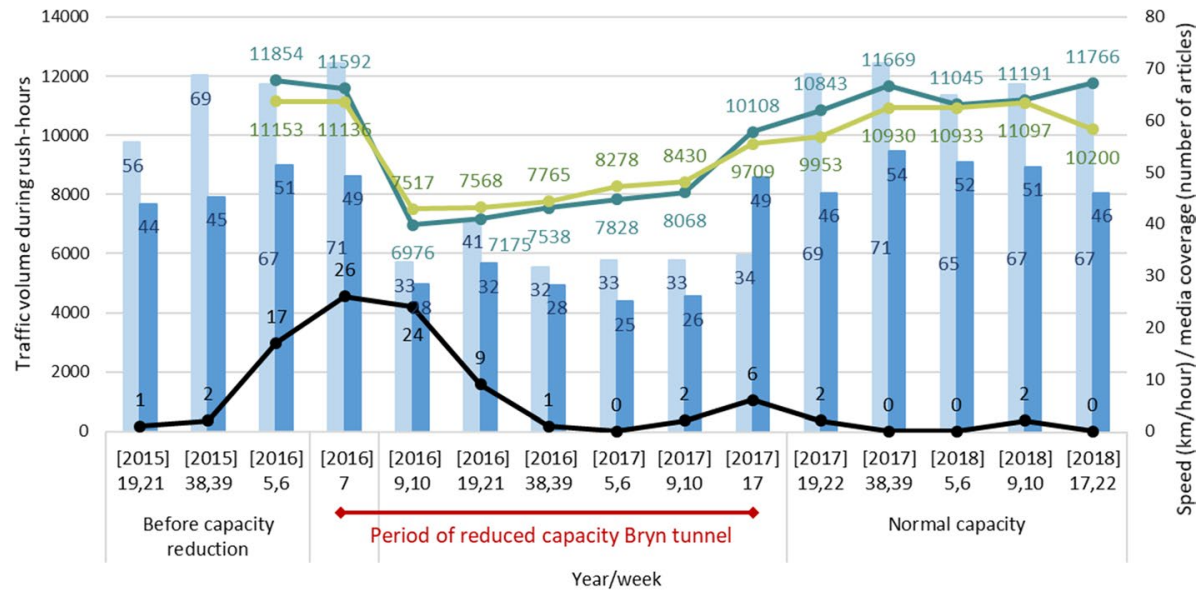

\footnotetext{
Teisen - Ryen / Ryen - Teisen - average traffic speed - both directions - morning rush hours 7-9

Teisen - Ryen / Ryen - Teisen - average traffic speed - both directions - afternoon rush hours 15-17

—300001 E6 Manglerud - traffic volume - both directions - morning rush hours 7-9

-300001 E6 Manglerud - traffic volume - both directions - afternoon rush hours 15-17

-Bryn tunnel - media coverage in newspapers (national press, regional and local newspapers, news agency)
}

Fig. 11 Bryn tunnel: media coverage and average traffic speeds during rush hour on the road link including the Bryn tunnel and average traffic volumes during rush hour at the nearby traffic counting point E6 Manglerud (total traffic, both directions) in selected weeks before, during and after the Bryn tunnel capacity reduction. The first week following the capacity reduction, week 8, was winter holiday in Greater Oslo. There is no registration of traffic volume for 2015

rehabilitation period, indicating that the tunnel had the capacity to handle the traffic volume during the work (see 4).

At Bryn, the situation was somewhat different. Figure 11 shows the same three parameters as above-media coverage, traffic speed and traffic volumes. In contrast to Smestad, media coverage for Bryn was lower in the week of capacity reduction, but it did not fall equally quickly in the following weeks (see also Fig. 8). When it comes to traffic volumes, a clear reduction started the week of tunnel rehabilitation and lasted until the tunnel was back in normal operation. Together with the persistent media coverage in the weeks following the capacity reduction, this indicates more traffic challenges in the rehabilitation period at Bryn compared with Smestad. Thus, the effects of the information campaign and media coverage on traffic volume are most evident in Smestad.

\section{The usage of social media}

Turning to the role of social media in the information campaign, the commuter surveys indicate this was a less important information source. Still, the NPRA's strategy of using FB as a way of reaching out represents an interesting change.

A way of measuring the reach of an FB post is looking at the level of engagement it creates. Such posts can be measured by the number of emoji reactions and comments they generate, as well as the number of times they are shared. Posted video clips can be 
measured by the number of times viewed. Interestingly, among the 15 NPRA posts with the most reactions, except one, all were paid advertisements. Such audience targeting digital advertising represents a new dimension in the NPRA communication strategy.

According to a key informant in the NPRA, the orientation towards social media created a clear shift in how the agency communicated with the public. The NPRA's strategy was that all comments received on the FB page were to be read, and direct messages and questions should be answered quickly. According to FB's statistics, the NPRA succeeded in doing this, with $82 \%$ of new messages receiving a first response from the agency on the same day.

With the new orientation towards social media, a shift in working procedures followed. This involved a transfer in communication with travellers from e-mail and telephone to social media. This also involved a shift from individual communication between the NPRA and travellers towards mass communication, as questions, comments and answers were made available to the wide group of followers of the Bryn tunnel FB page. In August 2017, some months after the rehabilitation work at Bryn ended, the Bryn tunnel FB page had 7240 followers. In addition, when the rehabilitation of the Bryn tunnel was finished, the NPRA continued to use the FB page, ${ }^{8}$ indicating the importance of social media for communicating with affected travellers and others.

\section{Discussion and concluding remarks}

In this paper, two NPRA information campaigns were analysed. These were related to the temporary capacity reductions of two main road tunnels, Smestad and Bryn, due to rehabilitation. The events involved closure of two of four lanes for 12 months at Smestad and 14 months at Bryn. Through a case-study approach, with the two tunnels constituting the cases, characteristics of the campaigns and their goal fulfilment were analysed. The analysis also involved the usage of social media as a new component of public communication.

\section{Motivation, content and execution of the information campaigns}

The tunnel rehabilitation in Oslo came as a response to requirements set by the EU's tunnel-safety directive. Ten tunnels in Oslo have been or are undergoing rehabilitation, and 200 will be rehabilitated at the national level. To analyse the campaigns, and inspired by Delhomme (2009), three categories were established: motivation, content strategy and execution strategy.

The motivation of the NPRA to initiate the campaigns seems to be twofold: First, they wanted to avoid severe congestion and traffic chaos resulting from the capacity reductions. Second, they wanted to avoid reputation damage from the tunnel rehabilitations. The campaigns were not only used to maintain given levels of traffic flows but also to inform affected travellers and tunnel neighbours about construction work disturbances or major incidents. In this way, and with a more diversified and lasting campaign at Bryn, public information was used to avoid rising levels of dissatisfaction (cf. Cairns et al. 2002).

\footnotetext{
${ }^{8}$ The FB page has now been renamed Oslo tunnels-in Norwegian, Oslotunneler, Statens vegvesen (https ://www.facebook.com/oslotunneler/).
} 
In terms of content strategy-that is, what was said-the NPRA's main message was twofold: First, the messaging was rather informative and said that the rehabilitation work would result in delays. Second, it encouraged travellers to remedy the situation by refraining from using cars. However, with the campaign at Smestad being much smaller and the main component being the dramatic mass-media headings of potential traffic chaos, it stands out as more one-dimensional and fear-based compared with the more multifaceted campaign for Bryn. In the latter, extensive information about work affecting traffic was given alongside encouragements and practical instructions on car alternatives. Despite clear normative elements in the Bryn campaign, it was mostly characterised by a positive approach, mixing humour with attempts of strengthening the travellers' skills (cf. Ostergaard 2011). Clearly, the campaign sought to build a broader understanding of transport-system workings and the importance of each traveller remedying the situation.

Turning to the NPRA's execution strategy - that is, how and by whom information is given - the handing out of flyers to neighbouring households, social media and mass-media coverage stand out as central components. In the Bryn campaign, the NPRA implemented new tools, including FB and paid advertising via both FB and digital media. The switch in strategy from the Smestad to Bryn tunnel involved the mass communication being increasingly targeted in both time and space. In line with the principle of audience-targeting advertising, the NPRA sought to reach residents in specific geographic areas (i.e. where inhabitants were likely to use the Bryn tunnel) and at defined times (e.g. morning). Pre-trip information was viewed as crucial for influencing travel behaviour (cf. Frey et al. 2011). This is in line with road-safety research, which has found that campaigns are more effective when focussed on specific groups (see Delhomme et al. 2009; Hoekstra et al. 2011; Wundersitz et al. 2010).

\section{Outreach and effects}

The surveys and qualitative interviews revealed high satisfaction with the NPRA information campaign among the relevant traveller groups. For Smestad and Bryn, 66 and $61 \%$ of commuters responded that they had received sufficient information prior to the capacity reduction. Further, the importance of traditional mass media as a source of information for different groups of travellers was illustrated. While editorial news coverage is not within the domain of the NPRA, the agency had a clear role in facilitating the tunnel rehabilitation's coverage by the media.

The media coverage was particularly strong and dramatic before the Smestad rehabilitation, communicating a high risk of congestion due to the capacity reduction. This resulted in many road users finding ways of avoiding driving through the Smestad tunnel and a steep drop in traffic volumes in the first days after the capacity reduction. When traffic jams and chaos failed to materialise, and the media reported this, the traffic volume soon returned to the original level. This is understood as a clear indication that the Smestad information campaign affected travel behaviour. At Bryn, the effects of the information campaign are not equally clear.

As described in section "Analytical categories to study information campaigns", the effectiveness of fear-based campaigns is uncertain. Delhomme et al. (2009) suggest such campaigns may be effective in specific situations. However, they point to the need for a solid knowledge base and pre-testing before implementing them. The findings 
concerning the Smestad case indicate that the fear-based public information had an effect in the first days after the capacity reduction. However, the rather free-flowing traffic was unexpected, including for the NPRA. This suggests that the knowledge base for the information campaign was not solid enough. As such, the information campaign caused many travellers to change their travel behaviour unnecessarily. This was part of the explanation of why the NPRA anticipated that they would not receive such media attention-and response to the campaign-again. Hence, when the tunnel with the most traffic, Bryn, was to be rehabilitated, an important tool had already been removed from the box. This helps explain why the Bryn campaign became both multifaceted and extensive.

\section{Social media: audience targeting and legitimacy}

As presented above, a two-step approach is recommended for information campaigns to, first, make people aware of the risks, and second, give people clear, actionable steps to reduce it (Jin et al. 2019). While both elements were present in the campaigns, the Bryn campaign was larger in terms of longevity and number of communication channels applied.

Smestad was heavily based on mass-media communication and the message was rather fear based. Knowing that the same media attention would not be received at Bryn, the campaign emphasised reaching travellers and neighbours throughout the rehabilitation period. The Bryn campaign clearly confirms how various media play different roles at specific crisis stages (cf. Liu et al. 2011). After having some media attention during the first three weeks of rehabilitation at Bryn, it faded. In contrast, the social-media activity endured throughout the rehabilitation period.

While the surveys indicated other channels were more important in terms of informing travellers about the forthcoming rehabilitation at Bryn, the NPRA's use of social media is worth further discussion for several reasons: First, social media had a clear role in building legitimacy for the tunnel rehabilitation, providing information about work affecting traffic and disturbances for neighbours. Advice, games and humour (with songs like 'Tunnel of love') were used to promote car alternatives. In addition, and in line with Cairns et al.'s (2002) recommendations, controversial issues were monitored, and critique was addressed. Last, the NPRA used social media to express understanding of the challenges travellers faced. Thus, while traditional media provided a basis for mass information in the early stages, social media had a mediating role throughout the rehabilitation period.

Second, the shift towards social media involved changes for both organisational working procedures of the NPRA and their ways of interacting with travellers. For the NPRA, the new use of social media involved a switch from individual communication with travellers via telephone and e-mail towards communication with a wider group on FB. The socialmedia usage also points towards a future landscape of public communication where broad social media and individually customised newsfeeds become more important. In this context, it is relevant that more than $83 \%$ of Norwegians 18 years or older have an FB profile. Daily use is high, and approximately $59 \%$ of Norwegian users also read edited news via FB. ${ }^{9}$ The relevance of FB as a communication channel is strong because of the number of

\footnotetext{
${ }^{9}$ Based on numbers from Ipsos' SoMe-tracker Q3'17 (https://www.ipsos.com/nb-no/ipsos-some-track er-q317, 02.01.2018).
} 
users, the possibility to reach followers via designated pages and the ease of distributing digital articles from newspapers.

Third, with the digital media advertising, the inclusion of social media in the information campaign illustrates new approaches to audience targeting to reach certain inhabitant groups at specific times. The Bryn tunnel was the first major project where such advertising was used, marking a shift in strategy. With this change, the public information became more targeted in both time and space.

\section{Concluding remarks}

For politicians and practitioners, the findings from this study are relevant in several ways. The importance of well-designed information campaigns to build legitimacy for public interventions has been emphasised both in relation to overall sustainability shifts (e.g. Banister 2008) and successful implementations of toll-road schemes (e.g. Livingstone 2004; Vonk Noordegraaf et al. 2014). However, while such campaigns may relate to national or local political ambitions of car-usage reduction or transport-infrastructure financing, the Oslo tunnel rehabilitations relate to sharpened EU tunnel-safety requirements. Still, the tunnel rehabilitation can inform the sustainable-transport discussion as both involve reallocation of urban road space. Initiatives to improve conditions for walking, cycling or public transport are often met with predictions that such changes in road structure will likely cause traffic problems (Cairns et al. 2002). Typically, attempts to reduce road capacity on one road are met with arguments about the need to build alternative roads for maintaining capacity. In the case of the Smestad and Bryn tunnels-which are among the busiest road stretches in Norway - this paper showed that traffic did not collapse during the period of capacity reduction, although the congestion challenges were more present in the latter (Tennøy et al. 2016, 2019).

The paper also provides knowledge for politicians and practitioners on the management of future urban roads maintenance. Tunnels and other central road links will regularly have long-term closures due to maintenance. However, through analysis of the motivation, content, execution and outreach of the information campaigns, the paper showed opportunities and pitfalls relevant beyond the realm of urban roads rehabilitation: It also highlighted critical factors in shifts towards more sustainable urban mobility.

Acknowledgements Open Access funding provided by Institute Of Transport Economics. The project Knowledge for future effective and environmentally sustainable urban transport systems, shortened BYTRANS, is financed by the Research Council of Norway (project number 257152) and user partners. We are grateful for the contributions of the other researchers in the core-team working with the BYTRANSproject at the Institute of Transport Economics. The following have in different ways contributed in data collection and analyses, but have not contributed directly to this article: Elise Caspersen, Iratxe Landa-Mata, Susanne Nordbakke, Kåre H. Skollerud, Jørgen Aarhaug and Tale Ørving. We are also grateful for the valuable comments from three anonymous reviewers.

Author contributions AT: Lead researcher in investigating information campaigns and their effects, including Conceptualization, Methodology, Investigation, Data Curation, Formal analysis, Writing original draft, Writing - review and editing this article. OHH: Methodology, Investigation, Formal analysis in the BYTRANS project, Key researcher in investigating information campaigns and their effects, including Conceptualization, Methodology, Investigation, Data Curation, Formal analysis, Writing original draft, Writing-review and editing this article. AT: Conceptualization, Methodology, Investigation, Formal analysis, Funding acquisition and Project administration of the BYTRANS project, Supervision, input to Writing original draft, and input to Writing - review and editing this article. 


\section{Compliance with ethical standards}

Conflict of interest On behalf of all authors, the corresponding author states that there is no conflict of interest.

Ethical standards Further, the study complies with Norwegian legal and ethical guidelines regulating data collection, storage, analysis and publication.

Open Access This article is licensed under a Creative Commons Attribution 4.0 International License, which permits use, sharing, adaptation, distribution and reproduction in any medium or format, as long as you give appropriate credit to the original author(s) and the source, provide a link to the Creative Commons licence, and indicate if changes were made. The images or other third party material in this article are included in the article's Creative Commons licence, unless indicated otherwise in a credit line to the material. If material is not included in the article's Creative Commons licence and your intended use is not permitted by statutory regulation or exceeds the permitted use, you will need to obtain permission directly from the copyright holder. To view a copy of this licence, visit http://creativecommons.org/licenses/by/4.0/.

\section{Appendix A: Overview of respondents and informants}

Table 1 Overview of respondents and informants

\begin{tabular}{|c|c|c|c|c|}
\hline & Survey & $\begin{array}{l}\text { Focus group } \\
\text { interview }\end{array}$ & $\begin{array}{l}\text { Individual } \\
\text { interview }\end{array}$ & $\begin{array}{l}\text { Follow-up } \\
\text { interview (same } \\
\text { informant) }\end{array}$ \\
\hline NPRA representatives & & 1 & 3 & 2 \\
\hline Interest organisations & & & 1 & \\
\hline Commuters & $\begin{array}{c}2(N=313 \text { and } \\
N=1029)\end{array}$ & & & \\
\hline Truck drivers & $1(N=32)$ & & 2 & \\
\hline Taxi drivers & & 3 & & \\
\hline Total & 3 & 3 & 6 & 2 \\
\hline
\end{tabular}

\section{Appendix B: Core questions in the qualitative interviews}

- What were the main information measures initiated to reduce traffic challenges during the tunnel rehabilitation?

- What were the main components in the information strategy to reduce congestion during the rehabilitation period?

- What were the main components in the information strategy to inform affected inhabitants and travellers about the rehabilitation work?

- What groups did you make a particular effort to reach?

o What strategies were applied to reach these groups?

o To what extent did you succeed in reaching these groups? 
- What feedback have you received from travellers in relation to the tunnel rehabilitation and the information campaign?

- To what extent did experiences from the Smestad tunnel rehabilitation lead to changes in the information campaign for the Bryn tunnel?

- What are the main lessons for future tunnel rehabilitations in relation to the information campaigns initiated at Smestad and Bryn?

\section{References}

Bafunno, D., Catino, A., Lamorgese, V., Pizzutilo, P., Di Lauro, A., Petrillo, P., Lapadula, V., Mastrandrea, A., Ricci, D., Galetta, D.: Tobacco control in Europe: a review of campaign strategies for teenagers and adults. Crit. Rev. Oncol. Hematol. 138(6), 139-147 (2019)

Banister, D.: The sustainable mobility paradigm. Transp. Policy 15(2), 73-80 (2008)

Cairns, S., Atkins, S., Goodwin, P.: Disappearing traffic? The story so far. Mun. Eng. 1(2001), 13-22 (2002)

Carey, R.N., McDermott, T.D., Sarma, K.N.: The impact of threat appeals on fear arousal and driver behavior: a meta-analysis of experimental research 1990-2011. PLoS ONE 8(5), e62821 (2013)

Chorus, C.G., Molin, E.J.E., Van Wee, B.: Use and effects of Advanced Traveller Information Services (ATIS): a review of the literature. Transp. Rev. 26(2), 127-149 (2006)

Christensen, A.S.P., Meyer, M.K.H., Dalum, P., Krarup, A.F.: Can a mass media campaign raise awareness of alcohol as a risk factor for cancer and public support for alcohol related policies? Prev. Med. 126, 105722 (2019)

Delhomme, P., De Dobbeleer, W., Forward, S., Simões, A. (eds.): Manual for Designing, Implementing, and Evaluating Road Safety Communication Campaigns. Directorate-General for Energy and Transport, European Commission, Brussels (2009)

Downs, A.: Why traffic congestion is here to stay ... and will get worse. ACCESS Mag. 1, 19-25 (2004)

European Parliament: Directive 2004/54/EC of the European Parliament and of the Council of 29 April 2004 on minimum safety requirements for tunnels in the Trans-European Road Network. (2004)

Frey, H., Leth, U., Mayerthaler, A., Brezina, T.: Predicted congestion never occur. On the gap between transport modelling and human behaviour. Transp. Probl 6(1), 73-85 (2011)

Hair, E.C., Cantrell, J., Pitzer, L., Bennett, M.A., Romberg, A.R., Xiao, H., Vallone, D.: Estimating the pathways of an antitobacco campaign. J. Adolesc. Health 63, 401-406 (2018)

Hoekstra, T., Wegman, F.: Improving the effectiveness of road safety campaigns: current and new practices. IATSS Res. 34(2), 80-86 (2011)

Jin, Y., Austin, L., Vijaykumar, S., Jun, H., Nowak, G.: Communicating about infectious disease threats: Insights from public health information officers. Public Relat. Rev. 45, 167-177 (2019)

Livingstone, K.: The challenge of driving through change: introducing congestion charging in central London. Plan. Theory Pract. 5(4), 490-498 (2004)

Liu, B.F., Austin, L., Jin, Y.: How publics respond to crisis communication strategies: the interplay of information form and source. Public Relat. Rev. 37, 345-353 (2011)

Lødding, B., Vibe, N.: Hvis noen forteller om mobbing. Rapport 48/10. Oslo, Nordisk institutt for studier av innovasjon, forskning og utdanning (NIFU). (2010)

Noland, R.B., Lem, L.L.: A review of the evidence for induced travel and changes in transportation and environmental policy in the US and the UK. Transp. Res. D 7(1), 1-26 (2002)

NPRA: Statens vegvesen Region east: communication strategy. Safe tunnels in Oslo. Internal note (2015a)

NPRA: Competitive basis for administrative services procurement. Purchase of preparation and distribution of information campaign for the Tunnel rehabilitation project Oslo. NPRA, Oslo (2015b)

Ostergaard, L.: Effective campaign assessment: how to learn from your failures. In: Klingemann, H.D., Röemmele, A. (eds.) Public Information Campaigns \& Opinion Research: A Handbook for the Student \& Practitioner, pp. 148-150. Sage Publications, London (2011)

Petrella, M., Lappin, J.: Comparative analysis of customer response to online traffic information in two cities Los Angeles, California, and Seattle, Washington transportation research record. J. Transp. Res Board TRB 1886, 10-17 (2004)

Phillips, R.O., Ulleberg, P., Vaa, T.: Do road safety campaigns work? A meta-analysis of road safety campaign effects. In: Forward, S., Kazami A. (eds.) A Theoretical Approach to Assess Road Safety Campaigns. CAST-project financed by EU's Sixth Framework Programme, published by Belgian Road Safety Institute (BIVV-IBSR), Brussels (2009) 
Taniguchi, A., Fujii, S., Azami, T., Ishida, H.: Persuasive communication aimed at public transportationoriented residential choice and the promotion of public transport. Transportation 41, 75-89 (2013)

Tennøy, A., Wangsness, P.B., Aarhaug, J., Gregersen, F.A.: Experiences with capacity reductions on urban main roads - rethinking allocation of urban road capacity? Open access: Transp. Res. Procedia 19, 4-17 (2016)

Tennøy, A., Caspersen, E., Hagen, O.H., Mata, I.L., Nordbakke, S., Skollerud, K.H., Tønnesen, A., Ørving, T., og Aarhaug, J.: BYTRANS: effects and consequences of capacity reduction in the Bryn tunnel. Documentation report. TØI report 1733/2019 (2019)

Vonk Noordegraaf, D., Annema, J.A., van Wee, B.: Policy implementation lessons from six road pricing cases. Transp. Res. A 59, 172-191 (2014)

Wundersitz, L.N., Hutchinson, T.P., Woolley, J.E.: Best practice in road safety mass media campaigns: a literature review. CASR Report Series, CASR074. University of Adelaide, Australia. https://citeseerx. ist.psu.edu/viewdoc/download?doi=10.1.1.457.3716\&rep=rep1\&type=pdf (2010).

Yin, K.Y.: Case Study Research. Design and Methods. Third edition. Sage Publications, Thousand Oaks (1994/2003)

Publisher's Note Springer Nature remains neutral with regard to jurisdictional claims in published maps and institutional affiliations.

Dr. Anders Tønnesen is human geographer and senior researcher at the Institute of Transport Economics, Oslo. His research focuses on environmental policy-making and climate-friendly urban development. In recent years he has paid particular attention to urban planning in relation to land-use and transport-system development, and the multi-level cooperation involved in these processes.

Oddrun Helen Hagen is a master of Science in Physical Planning, and a Research Planner at the Institute of Transport Economics, Oslo. Her experience covers planning of development areas, new infrastructure, streets and urban spaces. Her research focuses on car-free city centers, walkability, sustainable mobility within urban regeneration projects, effects and consequences of changes in transport systems, and multimodal travel and transfer.

Dr. Aud Tennøy, PhD Urban and Regional Planning, is Chief Researcher at the Institute of Transport Economics, Oslo. Main research interests are effects of land use and transport systems developments on traffic, environment and society, urban development for sustainable and attractive cities, planning and decisionmaking processes, the roles of planners in planning processes and use of knowledge in urban planning. 